\title{
Numerical framework and performance of the new multiple-phase cloud microphysics scheme in RegCM4.5: precipitation, cloud microphysics, and cloud radiative effects
}

\author{
Rita Nogherotto, Adrian Mark Tompkins, Graziano Giuliani, Erika Coppola, and Filippo Giorgi \\ The Abdus Salam International Centre for Theoretical Physics ICTP, Strada Costiera 11, 34151 Trieste, Italy \\ Correspondence to: Rita Nogherotto (rnoghero@ictp.it)
}

Received: 8 February 2016 - Published in Geosci. Model Dev. Discuss.: 10 March 2016

Revised: 7 June 2016 - Accepted: 5 July 2016 - Published: 27 July 2016

\begin{abstract}
We implement and evaluate a new parameterization scheme for stratiform cloud microphysics and precipitation within regional climate model RegCM4. This new parameterization is based on a multiple-phase one-moment cloud microphysics scheme built upon the implicit numerical framework recently developed and implemented in the ECMWF operational forecasting model. The parameterization solves five prognostic equations for water vapour, cloud liquid water, rain, cloud ice, and snow mixing ratios. Compared to the pre-existing scheme, it allows a proper treatment of mixed-phase clouds and a more physically realistic representation of cloud microphysics and precipitation. Various fields from a 10-year long integration of RegCM4 run in tropical band mode with the new scheme are compared with their counterparts using the previous cloud scheme and are evaluated against satellite observations. In addition, an assessment using the Cloud Feedback Model Intercomparison Project (CFMIP) Observational Simulator Package (COSP) for a 1-year sub-period provides additional information for evaluating the cloud optical properties against satellite data. The new microphysics parameterization yields an improved simulation of cloud fields, and in particular it removes the overestimation of upper level cloud characteristics of the previous scheme, increasing the agreement with observations and leading to an amelioration of a long-standing problem in the RegCM system. The vertical cloud profile produced by the new scheme leads to a considerably improvement of the representation of the longwave and shortwave components of the cloud radiative forcing.
\end{abstract}

\section{Introduction}

Despite the recent increase in computing power, the wide range of temporal and spatial scales involving cloud processes still requires parameterizations to allow the representation of clouds in current global and regional climate models (GCMs and RCMs, respectively). Convective clouds are represented by cumulus parameterizations, which mostly focus on dynamical and thermodynamical processes and treat the cloud microphysics in simplified ways. Stratiform, or resolved scale, clouds are represented by parameterizations employing more detailed treatments of cloud microphysics through the explicit prognostic simulation of one or more hydrometeors.

Simpler microphysics schemes treat the cloud water prognostically and precipitating water diagnostically (e.g. Rotstayn, 1997; Pal et al., 2000). Observational data show that between -23 and $0{ }^{\circ} \mathrm{C}$ the occurrence of supercooled water is not negligible (Matveev, 1984), and liquid and ice particles can co-exist for hours and sometimes even days (e.g. Korolev et al., 2003; de Boer et al., 2009). Often cloud schemes diagnose the fraction of cloud water in the ice phase based on the local temperature (e.g. DelGenio et al., 1996). The diagnostic partitioning of cloud water into the liquid and ice phases assumes implicitly that processes within the cloud are fast compared to the model time step, i.e. that the cloud variables are always in equilibrium. Therefore, a diagnostic representation is unable to describe the temporal variability and evolution of mixed-phase clouds, and a prognostic treatment of cloud ice and water is necessary to represent the microphysical processes of the two phases (including their contrasting sedimentation rates). More complex microphysics 
schemes have therefore been introduced to treat separately the cold and warm cloud microphysics by solving prognostic equations for cloud liquid water and ice (e.g. Fowler et al., 1996; Lohmann and Roeckner, 1996). These schemes are especially important as climate models approach resolutions at which cloud physics processes, including convection, need to be explicitly described without the use of parameterization schemes (e.g. Prein et al., 2015). Recently, several studies have illustrated the importance of using a more realistic representation of cloud microphysics in climate models. For example, Cesana et al. (2015) and Komurcu et al. (2014) showed that climate models tend to underestimate the supercooled liquid clouds, and models that prognose separately the liquid and ice mixing ratios give a better representation of cloud properties. The RegCM version 4 (or RegCM4) regional climate model of the International Centre for Theoretical Physics (ICTP) is a widely used system that has been applied to local and regional seasonal forecasting and climate change problems for all regions of the globe (e.g. Sylla et al., 2010; Diro et al., 2012a, b; Nogherotto et al., 2013; Coppola et al., 2014; Fuentes-Franco et al., 2014). The model has a wide choice of physical parameterizations for processes such as deep convection, but, to date, uses a simple diagnostic stratiform cloud scheme with a single prognostic cloud variable Pal et al. (2000). There is a need not only to improve the representation of the cloud processes in the RegCM modelling system, but also to conduct a comprehensive evaluation of the simulated clouds in RegCM integrations, which have received limited attention relative to the surface climate of the model.

In this paper we first present a description of the revised numerics and microphysics of the new five-phase prognostic parameterization scheme for stratiform clouds. The scheme is then tested in a series of experiments with the RegCM4 run using the tropical band configuration of Coppola et al. (2012), which allows an analysis of the scheme's performance in different climatic settings. The cloud variables are compared to the existing RegCM4 Subgrid Explicit Moisture Scheme (SUBEX), and the new parameterization is also assessed using the recently available Cloud Feedback Model Intercomparison Project (CFMIP) Observational Simulator Package (COSP, version 1.3.2) Bodas-Salcedo et al. (2011), which allows for direct comparison with a range of cloudrelevant satellite products, using model variables in a forward radiative transfer calculation to avoid uncertainties in retrieval techniques. The final section summarizes the findings and makes suggestions for future developments of the scheme.

\section{Methodology}

\subsection{Regional climate model}

The new cloud microphysics parameterization is introduced into International Centre for Theoretical Physics (ICTP) regional climate model RegCM version 4 . RegCM4 is a three-dimensional compressible, hydrostatic, primitive equation atmospheric model based on the dynamics of NCAR mesoscale model version 5 (MM5; Grell et al., 1994) and described in Giorgi et al. (2012). In the current version of RegCM4, the resolved-scale cloud microphysics is treated by the Subgrid Explicit Moisture Scheme (SUBEX, Pal et al., 2000), which calculates fractional cloud cover as a function of grid point average relative humidity and includes only one prognostic equation for cloud water. Rain is calculated diagnostically and it forms when the in-cloud liquid water exceeds a temperature-dependent threshold (autoconversion). Rain is assumed to fall instantaneously within the model's time step and to grow by accretion of cloud droplets. SUBEX does not treat cold cloud microphysics and the fraction of ice is diagnosed as a function of temperature in the RegCM4 radiation scheme from radiative transfer calculations (Giorgi et al., 2012). The diagnostic split of ice and liquid water assumes that below $-30^{\circ} \mathrm{C}$ clouds consist of ice and for temperatures above $-10^{\circ} \mathrm{C}$ clouds are liquid only. This representation is an augmentation of an earlier scheme (Giorgi et al., 1993, which was in turn a simplified version of the scheme of Hsie and Anthes, 1984).

\subsection{New microphysics cloud scheme}

The new cloud microphysics scheme considers cloud ice as a separate prognostic variable and also solves prognostic equations for rain and snow, accounting for the major microphysical pathways between these categories (Fig. 1). The scheme includes four hydrometeors in total: cloud liquid water and ice, rain, and snow. Each variable is expressed in terms of the grid-mean mixing ratio $q_{x}\left(\mathrm{~kg} \mathrm{~kg}^{-1}\right)$ and the governing equations for the mass mixing ratios of water vapour $q_{\mathrm{v}}$, cloud water $q_{\mathrm{c}}$, cloud ice $q_{\mathrm{i}}$, rain $q_{\mathrm{r}}$, and snow $q_{\mathrm{s}}$ take the form

$$
\frac{D q_{x}}{D t}=S_{i}+\frac{1}{\rho} \frac{\partial}{\partial z}\left(\rho V_{x} q_{x}\right)+D,
$$

where $S_{i}$ includes the microphysical source and sink terms for each hydrometeor, representing the conversion of water substance between microphysical categories (see Fig. 1). The second term on the right-hand side represents the source of the variable $q_{x}$ from the layer above due to gravitational sedimentation of the species falling with terminal velocity $V_{x}$. The substantive derivative on the left-hand side indicates that the prognostic equations include advection by the large-scale wind. Horizontal and vertical advection become increasingly important as horizontal resolution increases over time. The $D$ term on the right-hand side represents any transport or 


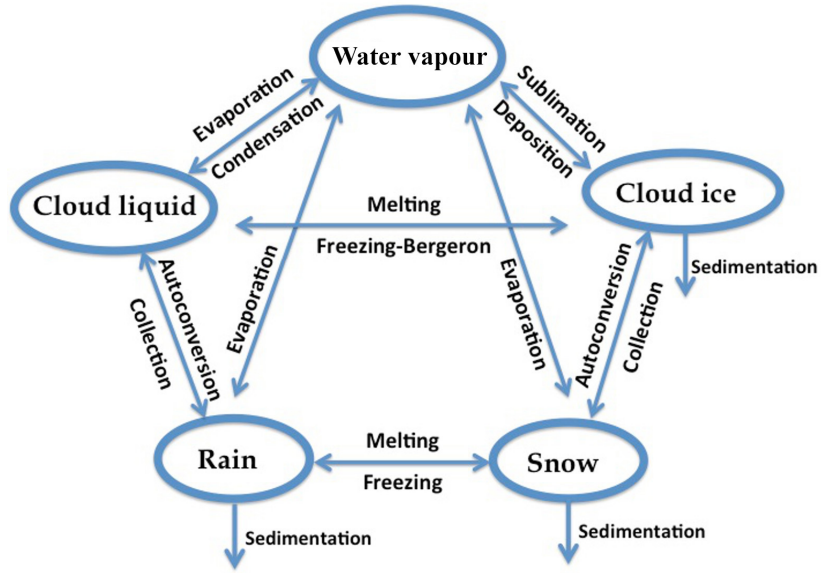

Figure 1. Sketch of the new scheme, showing the five prognostic variables and how they are related to each other through microphysical processes.

source/sink terms due to the other diabatic processes that are parameterized in the model, such as diffusion or deep convection.

The five prognostic equations for the individual species are solved using a simple forward-in-time, implicit solver approach that was implemented in the European Centre for Medium Range Weather Forecasts (ECMWF) integrated forecasting system (IFS) in cycle 31R1 (September 2006) with the objective of reducing the vertical-resolution sensitivity of the earlier explicit solver (Tompkins, 2005b). Tompkins subsequently generalized the IFS scheme to five species similar to the scheme presented here, which became operational in ECMWF cycle 36r4 (November 2010, Forbes et al., 2011). The scheme has the advantage of being conservative, numerically economical, and stable at all time steps, and employs a numerical solution framework that is trivially expandable to a larger number of microphysical variables, facilitating the future representation of hail and graupel categories, or various ice crystal size bins. However, Tompkins (2005b) emphasizes that the scheme is highly diffusive for fast falling species. Following Tompkins (2005b), the equations are solved using the upstream approach, which utilizes the forward difference quotient in time and the backward difference quotient in space. For the time step $n$, dropping the large-scale advection and diabatic contributions as these terms are handled elsewhere in the model outside the microphysics scheme, the discretized equations are

$$
\begin{aligned}
\frac{q_{x}^{n+1}-q_{x}^{n}}{\Delta t} & =A_{x}+\sum_{y=1}^{m} B_{x y} q_{y}^{n+1}-\sum_{y=1}^{m} B_{y x} q_{x}^{n+1} \\
& +\frac{\rho_{k-1} V_{x} q_{x, k-1}^{n+1}-\rho V_{x} q_{x}^{n+1}}{\rho \Delta z} .
\end{aligned}
$$

It is seen that the microphysical pathways have been divided between two terms $A$ and $B$, according to the timescale of the process they describe. Processes that are considered to be fast relative to the model time step, where the rate term can change substantially over the course of a time step (e.g. autoconversion), are treated implicitly and are included in matrix $B$. A positive term $B_{x y}$ represents a process which is a source of $q_{x}$ and a sink of $q_{y}$. Thus $B$ is positive-definite off the diagonal, with $B_{x x}=0$ by definition. On the other hand, processes that evolve slowly and can or should be assumed constant over a model time step (e.g. condensation by largescale ascent) are treated explicitly and are included in the matrix $A$ whose elements $A_{x}$ represent the net contribution to the variable $q_{x}$ by the explicit processes. We note that there is no definitive justification for how microphysical processes are allocated to each solution category. As sedimentation is in the downwards direction and there is no transport within the cloud scheme in the upward direction, the equations can be simply integrated one layer at a time from the top to the bottom layer of the model, making the solution numerically efficient, as in each layer the solution of a $m \times m$ matrix equation is required, where $m$ is the species number.

An $m=2$ category system at model level $k$ is given by:

$$
\begin{aligned}
& \left(\begin{array}{cc}
1+\Delta t\left(\frac{V_{1}}{\Delta z}+B_{21}\right) & -\Delta t B_{12} \\
-\Delta t B_{21} & 1+\Delta t\left(\frac{V_{2}}{\Delta z}+B_{12}\right)
\end{array}\right)\left(\begin{array}{l}
q_{1}^{n+1} \\
q_{2}^{n+1}
\end{array}\right) \\
& =\left(\begin{array}{c}
q_{1}^{n}+\Delta t\left(A_{1}+\frac{\rho_{k-1} V_{1} q_{1, k-1}^{n+1}}{\rho \Delta z}\right) \\
q_{2}^{n}+\Delta t\left(A_{2}+\frac{\rho_{k-1} V_{2} q_{2, k-1}^{n+1}}{\rho \Delta z}\right)
\end{array}\right)
\end{aligned}
$$

where the index $k-1$ represents the layer lying above the solution layer. Unlike implicit terms, explicit terms can possibly reduce a cloud variable to zero or negative values. In order to avoid this, and therefore to ensure that all variables remain positive definite at the end of the time step, the initial vector $\boldsymbol{A}$ containing the explicit source and sink terms is generalised using an anti symmetric matrix $A$, whose elements $A_{x y}>0$ represent a source for the variable $q_{x}$ and a sink for $q_{y}:$

$\left(\begin{array}{cc}A_{11} & A_{21} \\ -A_{12} & A_{22}\end{array}\right)$

All the terms in the diagonal, $A_{x x}$, represent microphysical sources that are considered "external" to the scheme, such as the cloud water detrainment from the (mass-flux) shallow and deep convection schemes. For each time step, before calling the solvers, the sum of all sinks of each variable is scaled to avoid negative values, a method that avoids negative values while guaranteeing total water conservation. For each microphysical pathway the change of phase is associated with a release or absorption of latent heat. Regarding the 
enthalpy budget, rather than summing the microphysics pathways (as in the schemes of Tiedtke, 1993; Swann, 1994, for example), which can easily give rise to coding errors and resulting non-conservation when modifying microphysical parameterizations in operational and/or evolving models, the source/sink is calculated using the explicit conservation of the liquid water temperature $T_{\mathrm{L}}$ defined as

$T_{\mathrm{L}}=T-\frac{L_{\mathrm{v}}}{C_{p}}\left(q_{1}+q_{\mathrm{r}}\right)-\frac{L_{\mathrm{s}}}{C_{p}}\left(q_{\mathrm{i}}+q_{\mathrm{s}}\right)$.

Since $\frac{\mathrm{d} T_{\mathrm{L}}}{\mathrm{d} t}=0$, the rate of change of the temperature is given by the equation

$$
\frac{\partial T}{\partial t}=\sum_{x=1}^{m} \frac{L_{x}}{C_{p}}\left(\frac{\mathrm{d} q_{x}}{\mathrm{~d} t}-D_{q_{x}}-\frac{1}{\rho} \frac{\partial}{\partial z}\left(\rho V_{x} q_{x}\right)\right),
$$

where $L_{x}$ is the latent heat (of fusion or evaporation, depending on the processes considered), $D_{q_{x}}$ is the convective detrainment, and the third term in the brackets is the sedimentation term. We subtract the convective detrainment term $D_{q_{x}}$ and the advective flux terms from the rate of change of species $q_{x}$ (due to all the processes) because they represent a net $T_{\mathrm{L}}$ flux not associated with latent heating with changes in phase of water in the scheme itself.

\subsubsection{Microphysics}

\section{Cloud cover}

Unlike the ECMWF IFS, the RegCM4 cloud fraction is not prognostic, but rather uses a diagnostic approach which has the advantage of simplifying the implementation and numerical cost but which has a number of disadvantages. The fractional cloud cover $C$ is calculated following the semiempirical cloudiness parameterization developed by $\mathrm{Xu}$ and Randall (1996), which uses the large-scale relative humidity $\mathrm{RH}$ and average condensate (cloud water and cloud ice) mixing ratios $\bar{q}_{1}=q_{1}+q_{\mathrm{i}}$ to give implicit information concerning the subgrid-scale total water distribution (see the review in Tompkins, 2002) and the resulting cloud cover:

$C=\left\{\begin{array}{ll}\mathrm{RH}^{p}\left[1-\exp \left(-\frac{\alpha_{0} \bar{q}_{1}}{\left[(1-\mathrm{RH}) q_{\mathrm{s}}\right.}\right]^{\gamma}\right] & \text { if } \mathrm{RH}<1 \\ 1 & \text { if } \mathrm{RH} \geq 1\end{array}\right.$,

where $p, \alpha_{0}$, and $\gamma$ are determined empirically and their values are $0.25,0.49$, and 100 , respectively. In theory, such a scheme also incorporates the impact of sub-grid temperature variability on cloud fraction, since temperature fluctuations are implicitly incorporated into the statistics of the cloud resolving model simulations to which the scheme is fitted; however, temperature fluctuations are likely underestimated in the small 2-D domains used in $\mathrm{Xu}$ and Randall (1996), although Tompkins (2005a) showed that temperature variability is in general far less important relative to total water variability above the boundary layer. One key disadvantage of using a diagnostic cloud fraction approach is that the treatment of ice supersaturation in the clear part of the model grid box at temperatures below $-38^{\circ} \mathrm{C}$, such as in the scheme of Tompkins (2007), is not permitted. This is because standard RH-based schemes (e.g. Sundqvist et al., 1989; Xu and Randall, 1996) diagnose overcast conditions when the grid box is saturated. Modifying the diagnostic relation to introduce a higher threshold for nucleation at cold temperatures (Koop et al., 2000) would not be able to represent the hysteresis between pre- and post-ice nucleation; in other words, a separate record is required of where in the grid-box nucleation has occurred. The Tompkins (2007) scheme was able to use the prognostic cloud fraction to accomplish this by assuming the nucleation and subsequent ice crystal diffusive growth timescales were fast compared to the model time step, thus assuming precisely ice-saturated conditions in the cloudy portion of the grid box. As stated by Tompkins (2007), this is a very good assumption if ice nucleation is predominately homogeneous in nature, although even if heterogeneous nucleation predominates it is still reasonable, since to cut off homonucleation completion IN concentrations need to be of an order of magnitude that results in the growth timescale being similar to a typical global model time step (Kärcher and Lohmann, 2002).

\section{Condensation and evaporation}

The formation of stratiform clouds associated with largescale lifting of moist air or with radiative cooling is treated as a function of the variation in time of the saturation mixing ratio, following Tiedtke (1993). In fact, if the saturation mixing ratio decreases, condensation occurs, while as it increases, evaporation takes place. The variation in time of the saturation mixing ratio can be written as

$\frac{\mathrm{d} q_{\mathrm{sat}}}{\mathrm{d} t}=\left.\frac{\partial q_{\mathrm{sat}}}{\partial T} \frac{\partial T}{\partial t}\right|_{\mathrm{diab}}+\left.\frac{\partial q_{\mathrm{sat}}}{\partial p}\right|_{\mathrm{ma}} \omega$.

This equation shows that the rate of change of the saturation mixing ratio is linked to diabatic cooling $(\partial T / \partial t)_{\text {diab }}$ and to the vertical motion with a grid mean vertical velocity $\omega$, where $\left(\partial q_{\mathrm{sat}} / \partial p\right)_{\mathrm{ma}}$ is the variation of $q_{\text {sat }}$ along a moist adiabat. Condensation occurs when

$\frac{\mathrm{d} q_{\mathrm{sat}}}{\mathrm{d} t}<0$

The condensation rate $C_{1}$ is proportional to the amount of cloud and is equal to

$C_{1}=-C \frac{\mathrm{d} q_{\mathrm{sat}}}{\mathrm{d} t}, \quad \frac{\mathrm{d} q_{\mathrm{sat}}}{\mathrm{d} t}<0$,

and all the increase in cloud amount is a source of cloud water unless the process occurs within cold clouds, in which case deposition occurs and ice forms. Due to the diagnostic 
treatment of the cloud fraction, homogeneous freezing takes place and removes any supersaturation instantaneously.

The scheme treats two processes that induce evaporation: the large-scale descent and the diabatic heating, giving rise to $E_{1}$, and the turbulent mixing of cloud air with drier environmental air, producing $E_{2}$, so that the total evaporation $E$ is given by

$E=E_{1}+E_{2}$.

In contrast to condensation, evaporation is proportional to the increase in the saturation mixing ratio and to the amount of cloud following

$E_{1}=C \frac{\mathrm{d} q_{\mathrm{sat}}}{\mathrm{d} t}, \quad \frac{\mathrm{d} q_{\mathrm{sat}}}{\mathrm{d} t}>0$.

It is reasonable to assume that the cloud water content within clouds is homogeneously distributed in the horizontal direction; therefore, the evaporation does not change the cloud cover until it decreases to zero. In order to calculate $E_{2}$, a very simple treatment of turbulence mixing is adopted in this first version of the scheme that duplicates the approach of Tiedtke (1991) by treating turbulence as a sink of cloud water. As discussed by Tompkins (2002, 2005a), the sign of the turbulent impact on cloud water is only correct if the total water mixing ration $\bar{q}_{1}=q_{1}+q_{\mathrm{i}}$ is smaller than the saturation mixing ratio; otherwise, mixing leads to an increase in cloud water. The intention is to correct this when a PDFbased cloud cover parameterization is later implemented.

\section{Condensation from detrainment}

As an input from the convection scheme, the microphysics scheme receives the detrained mass flux $D$ that is assumed to condense into cloud water or into ice diagnostically using a coefficient $\alpha$ function of temperature. This process is applied for all types of convection, namely deep, shallow, and midlevel, and represents an important extension of the model's cumulus parameterization.

The source of water/ice cloud content is given by

$$
\frac{\partial q_{x}}{\partial t}=\alpha(T) D_{x},
$$

where $x$ represents either ice or liquid according to the value of a function of the temperature $\alpha(T)$.

\section{Autoconversion}

Autoconversion is the mechanism by which rain or snow droplets form from the aggregation of cloud water or ice particles. This process plays a crucial role in the development of precipitation. For this reason we have implemented four different parameterizations of the process, all following the form

$P=P_{0} \cdot T$ where $P$ is the autoconversion rate, $P_{0}$ the autoconversion rate once the autoconversion has started, and $T \leq 1$ a function that describes the threshold behaviour of this process (Liu and Daum, 2004). The four parameterizations of autoconversion in the scheme, which can be selected by the user, employ different threshold functions: an "all-or-nothing" approach, described in Kessler (1969),

$$
\begin{gathered}
\frac{\partial q_{\mathrm{r}}}{\partial t}=k \cdot\left(q_{1}-q_{\text {crit }}\right) \quad\left(\text { with } k=10^{-3} \mathrm{~s}^{-1}\right. \\
\text { and } \left.q_{\text {crit }}=0.5 \mathrm{~g} \mathrm{~m}^{-3}\right)
\end{gathered}
$$

and three exponential approaches using smooth threshold functions.

The first follows Sundqvist (1978):

$$
\begin{aligned}
& \frac{\partial q_{\mathrm{r}}}{\partial t}=c_{0} F_{1} q_{1}\left\{1-\exp \left[-\left(\frac{q_{1}^{\text {cld }}}{q_{1}^{\text {crit }}}\right)^{2}\right]\right\}, \\
& \left(\text { with } F_{1}=1+b_{1} \sqrt{P_{\text {loc }}}\right. \text { ), }
\end{aligned}
$$

where $c_{0}=1.67 \times 10^{-4} \mathrm{~s}^{-1}, b_{1}=100\left(\mathrm{~kg} \mathrm{~m}^{-2} \mathrm{~s}^{-1}\right)$, and $P_{\mathrm{loc}}$ is the local cloudy precipitation rate.

The second parameterization follows Beheng (1994):

$$
\frac{\partial q_{\mathrm{r}}}{\partial t}=c_{b} \cdot q_{1}^{3.3} \quad\left(\text { where } c_{b}=2.461 \times 10^{5} \mathrm{~s}^{-1}\right),
$$

and the third following Khairoutdinov and Kogan (2000):

$$
\frac{\partial q_{\mathrm{r}}}{\partial t}=c_{k k} \cdot q_{1}^{2.47} \quad\left(\text { where } c_{k k}=0.355 \mathrm{~s}^{-1}\right) \text {. }
$$

The autoconversion of cloud droplets distinguishes between maritime and continental clouds by considering two different values for the cloud droplet concentration number $N$ (Beheng, 1994). The parameterization used for autoconversion of ice follows Eq. (14) but with different parameters more appropriate for ice particles with a coefficient $c_{0}$ that is a function of the temperature $T$ (Lin et al., 1983):

$c_{0}=10^{-3} \exp (0.025 \cdot(T-273.15))$.

Here, the default autoconversion parameterization is set to Sundqvist's scheme (Eq. 14), and sensitivity studies using different autoconversion schemes need to be carried out for specific applications.

\section{Freezing and melting}

The parameterization of ice crystal nucleation is very simple and takes into account only the homogeneous process, with the ice number concentration $\left(N_{\mathrm{i}}\right)$ diagnosed according to Meyers et al. (1992). For temperatures below the homogeneous nucleation threshold of $-38^{\circ} \mathrm{C}$, water droplets are assumed to freeze instantaneously. For temperature above this threshold, supercooled water and ice are allowed to coexist; 
they are assumed to be well mixed and are distributed uniformly through the cloud. At temperatures below this threshold the liquid water is assumed to freeze instantaneously, and the process is a source of cloud ice. The ice crystal is then assumed to grow at the expense of the water droplets through the Wegener-Bergeron-Findeisen process following Rotstayn et al. (2000). The melting of ice and snow is parameterized taking into account also the cooling due to the evaporation of liquid water during the melting process. Therefore, the wet-bulb temperature is used instead of the dry-bulb one. Melting occurs if the wet-bulb temperature is greater than $0^{\circ} \mathrm{C}$. The part of the box containing precipitation is allowed to cool to $T_{\text {melt }}=0{ }^{\circ} \mathrm{C}$ over a timescale $\tau$. The wet-bulb temperature $T_{\mathrm{W}}$ is parameterized through a numerical approximation suggested by Wilson and Ballard (1999). All rain freezes in a time step if the temperature is lower than $0^{\circ} \mathrm{C}$. This process represents a sink for rain and a source of snow. Since freezing would lead to an increase in temperature due to the latent heat release, the scheme ensures that the temperature does not exceed the $0{ }^{\circ} \mathrm{C}$ threshold. For a more detailed description of the parameterization of microphysical processes, we refer the reader to the IFS documentation, Cy40r1, Part IV: Physical Processes (online at https://software.ecmwf.int/wiki/display/IFS/Official+ IFS+Documentation).

\subsubsection{Simulation experiments}

Table 1 describes the simulation experiments conducted and analysed in this work. We completed two 10-year simulations: one using the SUBEX scheme of the standard RegCM4 (hereafter referred to as "SUB") and one with the newly implemented microphysics cloud scheme (hereafter referred to as "MIC"). Both simulations begin on 1 January 2000 and end on 1 January 2010. However, the first 5 months of the simulation, i.e. up to May 2000, are not included in the analysis as the initial spin-up period. As already mentioned, in order to obtain a general overview of the model's ability in representing clouds for different climate settings, the model is run over a tropical band domain $\left(180^{\circ} \mathrm{W}-180^{\circ} \mathrm{E}, 47^{\circ} \mathrm{S}-\right.$ $47^{\circ} \mathrm{N}$ ), as in Coppola et al. (2012), with a horizontal resolution of $90 \mathrm{~km}$ and 23 vertical sigma levels. Initial and lateral (northern and southern) boundary conditions are obtained from the ERA-Interim $0.75^{\circ} \times 0.75^{\circ}$ reanalysis (Simmons et al., 2007; Dee et al., 2011). Among the many physics schemes available in RegCM4 (Giorgi et al., 2012), in this study we use the mass flux convection scheme of Tiedtke (1989), the Biosphere-Atmosphere Transfer Scheme BATS (Dickinson et al., 1993) for land surface processes, and the boundary layer scheme of Bretherton et al. (2004), which provides a realistic representation of stratocumulus-capped boundary layers. For a more detailed understanding of the impact of the new scheme on the representation of clouds and cloud radiative forcing (CRF), the results of a 1-year test run (2007) are analysed and compared to observations us- ing the Cloud Feedback Model Intercomparison Project Observational Simulator Package COSP (Bodas-Salcedo et al., 2011) for both the SUB and MIC model configurations. The monthly mean COSP fields are produced from each 6-hourly RegCM4 output and then averaged over the months and seasons. This analysis is limited to 1 year, as in most previous studies (e.g. Franklin et al., 2013; Sud et al., 2013), because of the large amount of processing it requires.

\section{Results}

In this section we compare the SUB and MIC simulations for precipitation, total cloud cover, vertical cloud distribution, and CRF. The model output is assessed against different observational data sets, with the focus on the two extreme seasons, December-January-February (DJF) and June-JulyAugust (JJA).

\subsection{Precipitation}

An unambiguous assessment of the effect of the new scheme on precipitation performance is extremely difficult. On the one hand, the simulation of precipitation is sensitive to the use of different physics schemes in the model, with this sensitivity depending on region and season (e.g. Giorgi et al., 2012; Coppola et al., 2014). On the other hand, observed precipitation in tropical regions is characterized by a substantial level of uncertainty (e.g. Nikulin et al., 2012; Sylla et al., 2013). It is thus likely that the MIC and SUB schemes might show different performances when used with different sets of model configurations or compared with different observation data sets. Exploring this sensitivity would require a large multi-physics model ensemble which is beyond the purpose of the present paper. Rather, the more limited objective of this section is to illustrate the effect of the MIC scheme with respect to the SUB one within the framework of a model configuration yielding a realistic precipitation simulation in tropical band mode. Figure 2 shows the DJF and JJA 10-year precipitation climatologies for the SUB and MIC runs along with the corresponding precipitation patterns in the Tropical Rainfall Measuring Mission (TRMM) (Huffman et al., 2007) observation data set. Both model configurations produce a good spatial representation of the Intertropical Convergence Zone (ITCZ) and South Pacific Convergence Zone (SPCZ), with maxima in convective precipitation generally following observations. Also captured are the mid-latitude winter storm tracks over the Atlantic and Pacific mid-latitudes, as well as the main monsoon regions of South America, Africa, India, and East/South-east Asia. Overall, the main difference between the two schemes is that the MIC tends to be wetter than the SUB over the oceans and drier over the continental masses. For the present model configuration and in comparison with the TRMM data, this tends to yield an improved agreement with observations over land and a deterioration 

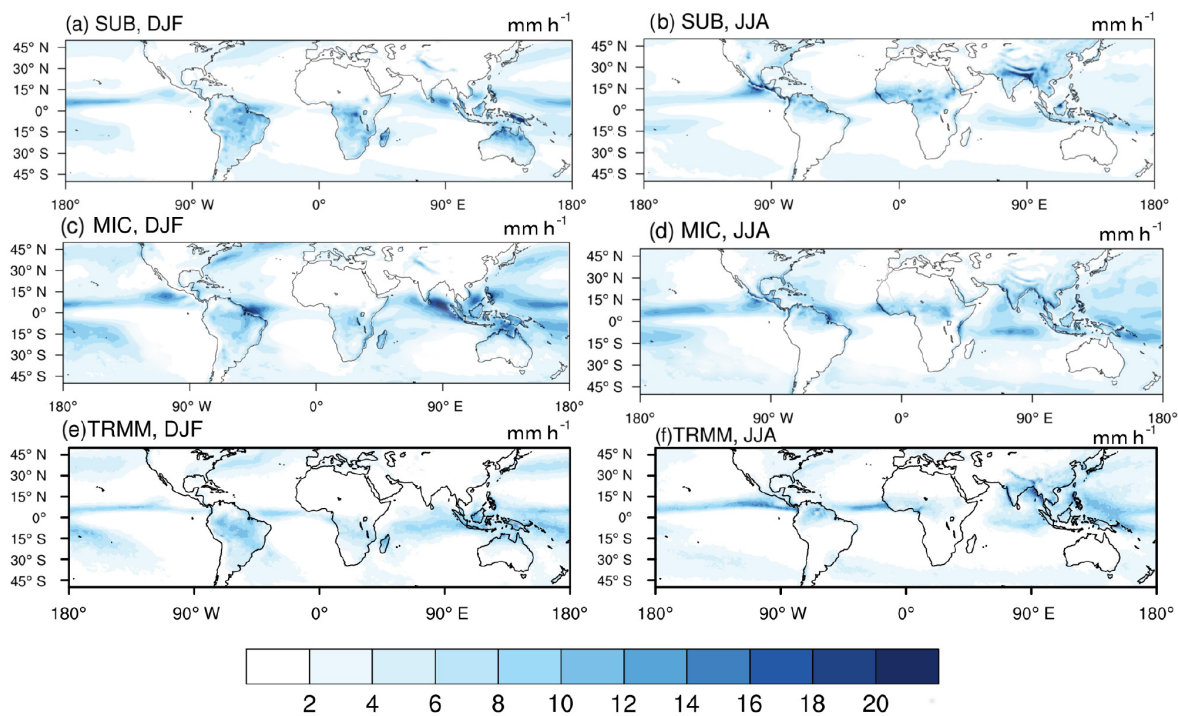

Figure 2. Simulated 10-year mean precipitation $\left(\mathrm{mm} \mathrm{h}^{-1}\right)$ for DJF (left) and JJA (right) in SUB and MIC runs (top two panels) and OBS (bottom); TRMM data represent OBS.

Table 1. Description of simulation experiments.

\begin{tabular}{lll}
\hline Simulation experiments & Descriptions & Year analysed \\
\hline SUBEX run (SUB) & RegCM4 with baseline cloud physics & 10 \\
MICROPHYSICS run (MIC) & RegCM4 with the new cloud microphysics scheme & 10 \\
SUB run with COSP simulator & Cloud properties from ISCCP, CALIPSO, MISR simulator & 1 \\
MIC run with COSP simulator & Cloud properties from ISCCP, CALIPSO, MISR simulator & 1 \\
\hline
\end{tabular}

over oceans. As already mentioned, this conclusion likely depends on the model configuration; however, it is clear from Fig. 2 that the new microphysics produces a realistic simulation of precipitation, particularly over land, throughout the tropics and sub-tropics. It should also be mentioned that the MIC scheme itself is sensitive to different parameters affecting the production of precipitation, and in particular the ice and snow fall speed and the choice of the autoconversion threshold (Nogherotto, 2015).

\subsection{Cloud fractions}

In this section we present an analysis of the cloud fractional cover. This is accomplished by applying the COSP post-processing tool to the model output to produce cloud variables comparable to those observed. As already mentioned, this post-processing was carried out only for the seasons December 2006 to February 2007 (DJF) and June to August 2007 (JJA), following the evaluation of clouds in the ACCESS model by Franklin et al. (2013). Total cloud fractions are calculated by the model using the approach of Xu and Randall (1996) and the max-random overlap assumption. The evaluation of total cloud cover is carried out using the GCM simulator-oriented International Satel- lite Cloud Climatology Project (ISCCP) cloud product (Pincus et al., 2012), which was prepared to facilitate the evaluation of the model-simulated clouds within the framework of the Cloud Feedback Model Intercomparison Project (http://climserv.ipsl.polytechnique.fr/cfmip-obs). Data are averaged over the JJA and DJF 2007 seasons during the daytime, at a horizontal resolution of $2.5^{\circ} \times 2.5^{\circ}$. Figure 3 shows the total cloud cover in the SUB and MIC simulations for the selected seasons, post-processed with COSP's ISCCP simulator. These are compared with the corresponding observed ISCCP total cloud amounts for the same seasons (Fig. 3e and f). The ISCCP's observed total cloud fraction averaged over the domain is 66.07 and $64.66 \%$ for DJF and JJA, respectively. These values are $68.44 \%$ in DJF and $65.35 \%$ in JJA for the SUB run, and $61.52 \%$ in DJF and $60.04 \%$ in JJA for the MIC (Table 2). Therefore, the SUB scheme produces generally larger cloud fractions than the MIC, and the observations lie within the two model configuration data. In general, both schemes capture the horizontal distribution of clouds over the band domain in both seasons, with maximum cloud cover over the ITCZ and the mid-latitude storm track regions of both hemispheres. However, an analysis of the spatial correlation between the two schemes and the observations reveals that the new parame- 


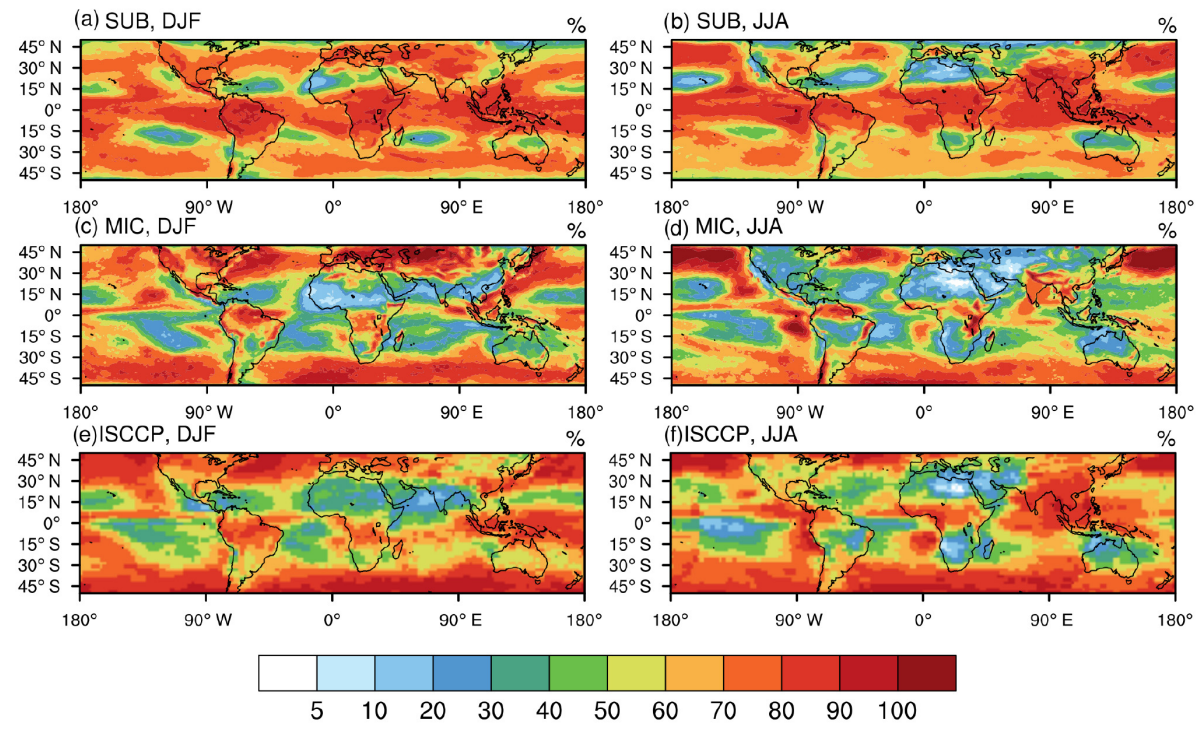

Figure 3. RegCM4 simulations using the ISCCP simulator using the SUB scheme for DJF (a) and JJA, and using the MIC scheme for DJF (c) and for JJA (d). Satellite observations of ISCCP total cloud amounts (unit in \%) for JJA (a) and DJF (c).

Table 2. Global means (and spatial correlations with observations) of total cloud fractions for JJA and DJF 2007 of SUB and MIC vs. observations.

\begin{tabular}{lrrr}
\hline Fields & $\begin{array}{r}\text { RegCM4 (SUB) } \\
\text { ISCCP simulator mean (corr) }\end{array}$ & $\begin{array}{r}\text { RegCM4 (MIC) + } \\
\text { ISCCP simulator mean (corr) }\end{array}$ & Obs: ISCCP mean \\
\hline Total cloud fraction - JJA (\%) & $67.35(0.39)$ & $60.04(0.69)$ & 64.66 \\
Total cloud fraction - DJF (\%) & $68.44(0.32)$ & $61.52(0.67)$ & 66.07 \\
\hline
\end{tabular}

terization improves the horizontal distribution of clouds (Table 2): while the SUB scheme tends to overestimate the magnitude and extension of total cloud amounts across the ITCZ, the MIC scheme shows a slight underestimation, but it improves the stratiform cloud cover between 30 and $45^{\circ} \mathrm{S}$, yielding higher spatial correlation values compared to those obtained with SUB. For a more detailed investigation of the model clouds' representation, we calculated the contributions from the high (50-440 hPa, mainly cirrus and deep cumulus clouds), mid (440-680 hPa) and low (>680 hPa, mainly shallow cumulus and stratocumulus) level clouds and compared them with estimates from the Cloud-Aerosol Lidar and Infrared Pathfinder Satellite Observations (CALIPSO, Winker et al., 2010) data. These are shown for JJA (results are similar for DJF) in Fig. 4. The GCM-Oriented CALIPSO Cloud Product (GOCCP) data (Chepfer et al., 2010), $2^{\circ} \times 2^{\circ}$, are used for the model evaluation as they are designed for comparisons with output from the CALIPSO satellite simulator. In the observations high clouds occur along the ITCZ, and especially over the tropical continental areas and over the mid-latitude storm track regions. Mid-level clouds are also prominent in the storm track regions and some tropical areas, while low clouds, including shallow cumulus and stratiform clouds, are prevalent over cooler subtropical oceans, in correspondence to the descending branch of the Hadley cell. Both model versions capture rather well the distribution of low clouds, except over the southern oceans, where only the MIC simulated some shallow stratiform cloud cover. The low level cloud cover averaged over the domain is essentially the same in the two schemes (Table 3), and slightly lower than the CALIPSO product. The largest differences between the two schemes occur in the simulation of high and medium level clouds. Compared to the SUB scheme, the MIC produces much lower values of high clouds $(\sim 25 \%$ vs. $\sim 64 \%$ for the domain average) and greater values of midlevel clouds $(\sim 11 \%$ vs. $\sim 7 \%)$, in both cases considerably increasing the agreement with the CALIPSO data. A possible explanation could be related to the different approach in treating the convective detrainment: while in MIC the detrainment produced by the convection scheme is given as an input to the microphysics scheme and is therefore subjected to microphysical processes, in SUB the detrainment is a source of cloud liquid water and is not involved in the formation of rain until the following time step. Another possibility is that the SUB scheme does not include ice physics, which would be dominant at high altitudes. For example, ice crystals tend to aggregate faster than liquid droplets and thus precipitate more efficiently to lower levels. Note that the dif- 

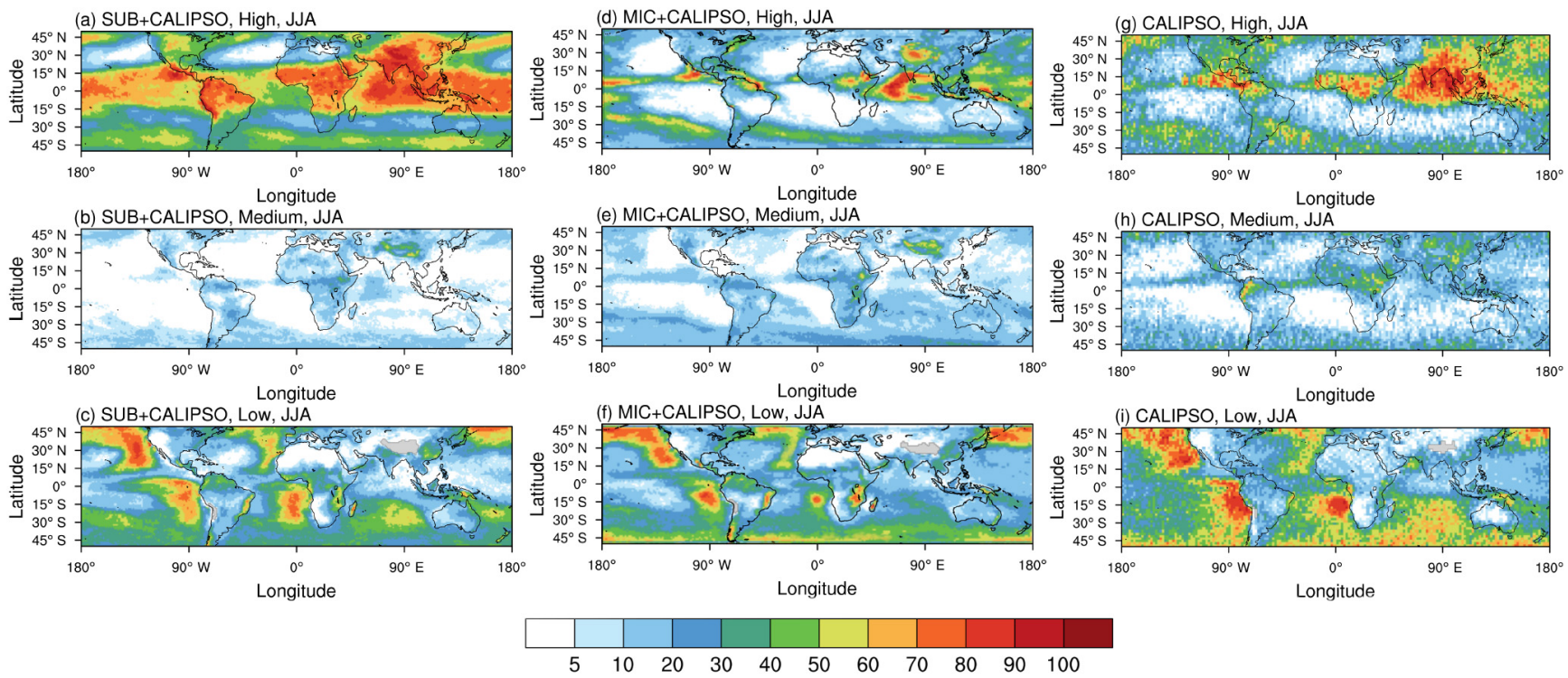

Figure 4. Left panels show RegCM4's high, middle, and low clouds (from top to bottom) using SUB and the CALIPSO simulator for during JJA 2007 (unit in \%). Middle panels show the same fields using MIC and right panels show CALIPSO observations.

Table 3. Global means of high, medium, and low clouds of SUB and MIC vs. observations.

\begin{tabular}{lrrr}
\hline Fields & $\begin{array}{r}\text { RegCM4 (SUB) }+ \\
\text { CALIPSO simulator mean }\end{array}$ & $\begin{array}{r}\text { RegCM4 (MIC) }+ \\
\text { CALIPSO simulator mean }\end{array}$ \\
\hline High clouds $(50-440 \mathrm{hPa})(\%)$ & 64.33 & 24.85 & 31.97 \\
Medium clouds $(440-680 \mathrm{hPa})(\%)$ & 6.62 & 11.10 & 16.53 \\
Low clouds $(>680 \mathrm{hPa})(\%)$ & 29.22 & 29.10 & 35.59 \\
\hline
\end{tabular}

ference in the results between the assessments with the ISCCP (Fig. 3) and CALIPSO (Fig. 4) data suggests that the SUB scheme tends to overestimate optically thin clouds not detected by ISCCP. In fact, ISCCP is able to detect clouds with optical depths greater than $0.15-0.25$ (over ocean and land), while CALIPSO can measure optically thinner clouds with depths greater than 0.03 (Rossow et al., 1996). An even more accurate analysis of cloud vertical distribution can be carried out with the use of the Multi-angle Imaging SpectroRadiometer MISR (Muller et al., 2002) data. MISR uses nine cameras providing images with approximately $275 \mathrm{~m}$ sampling in four narrow spectral bands, spanning much of the angle range over which cloud reflectivity varies. This leads to a more accurate retrieval of albedo than with the use of a single camera. Naud et al. (2002), however, found that in the case of multi-layered clouds, MISR often "sees" through the thin upper level clouds and mostly refers to low level cloud layers. The MISR retrievals can be processed to produce joint histograms of cloud top height (CTH) and optical depth (OD) used specifically for a comparison with the COSP output and available on the CFMIP observational data-set website. To compare with the MISR retrievals, we post-processed the RegCM4 data with the MISR simulator described in Marc- hand et al. (2010). Figure 5 reports the MISR histograms of optical depth vs. cloud top height averaged over the tropical band domain. It shows a bimodal distribution of cloud elevations, with two maxima in cloud fractions. One occurs at low altitudes, between 0 and $2.5 \mathrm{~km}$, across a range of optical depths, from 0.8 to 16.2. The second is found at higher levels, between 5 and $9 \mathrm{~km}$, with optical depths of 2.45-16.2. Post-processing the SUB output with the MISR simulator confirms an overestimation of high, thin clouds with optical depths lower than 2.45 , along with thicker clouds with optical depths higher than 16.20. The MIC post-processed output tends to underestimate low optical depth clouds $(\tau<16.2)$ and to overestimate high clouds with optical depths greater than 41.5. As already found using the CALIPSO simulator, the main differences between the two schemes occur in the simulation of high clouds. Both schemes show a tendency to underestimate thin low clouds with optical depths lower than 2.45, although the MIC's low clouds exhibit a wider range of optical depths more in line with observations. While an underestimation of low clouds is a common problem in climate models (e.g. Nam et al., 2012; Zhang et al., 2005) a reason for the overestimation of thick clouds found here may reside in the fact that even if in real systems only part of a $100 \mathrm{~km}$ 

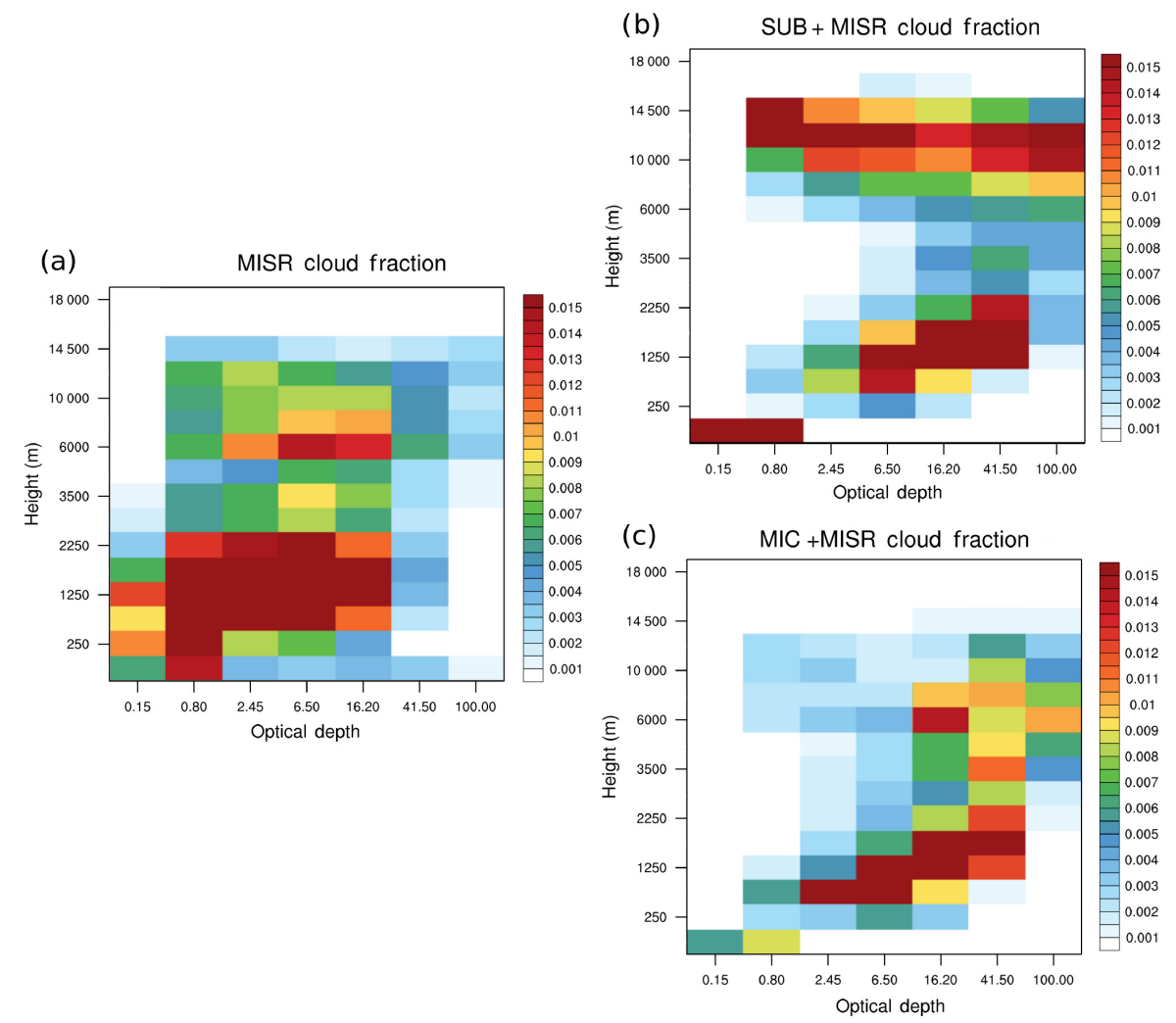

Figure 5. (a) Joint histograms of cloud top height and optical depth for MISR observations for JJA. (b) Joint histograms of cloud top height and optical depth for SUB using the MISR simulator for JJA. (c) Joint histograms of cloud top height and optical depth for MIC using the MISR simulator for JJA. The colour scale represents the cloud fraction in non-dimensional units, from 0 to 1.

grid area experiences a strong upward motion, the mean vertical velocity for the whole model grid box is upward, leading to an updraft for the entire grid box. A reason for the overestimation of low optically thick clouds can be related to the coarse horizontal model resolution $(100 \mathrm{~km})$ which does not resolve surface-heterogeneity, topography, and shallow mesoscale circulations. Future studies will evaluate the model performance at higher horizontal resolutions.

\subsection{TOA cloud radiative forcing}

In this section we assess the cloud influence on the model radiation budget via an analysis of the CRF (Ramanathan et al., 1989), defined for the shortwave (SW) and longwave (LW) spectra as

$\mathrm{CRF}=F^{\mathrm{cld}}-F^{\mathrm{clr}}$,

where $F$ is the net downward (i.e. downward minus upward) shortwave (SW) or longwave (LW) flux, the index clr designates clear sky, and cld designates all-sky conditions. The CRF is calculated at the top of the atmosphere (TOA), for which observations are more reliable. The simulated CRFs are compared to the corresponding fluxes from the Clouds and the Earth's Radiant Energy System CERES
ERBA-like Monthly Geographical Averages (ES-4) observations (Wielicki, 2011), with a horizontal resolution of $2.5^{\circ} \times 2.5^{\circ}$. Figure 6 shows the TOA CRF $\mathrm{LW}_{\mathrm{LW}}$, where the values are positive because the net upward TOA LW flux is greater with clear skies than with cloudy skies due to the relatively low temperatures of clouds. The figure indicates that MIC matches observations much better than SUB. The $\mathrm{CRF}_{\mathrm{LW}}$ biases in SUB and MIC simulations are consistent with those of the cloud fraction: with MIC the model simulates a smaller $\mathrm{CRF}_{\mathrm{LW}}$ because its clouds are lower and less extensive than with SUB, where the large overestimate of high clouds reduces excessively the infrared cooling to space. Overall the SUB scheme overestimates the domain-average $\mathrm{CRF}_{\mathrm{LW}}$ by $38 \mathrm{~W} \mathrm{~m}^{-2}$, while the MIC is much closer to observations, with a bias of $8 \mathrm{~W} \mathrm{~m}^{-2}$ (see Table 4).

Figure 7 shows the simulated and observed $\mathrm{CRF}_{\mathrm{SW}}$. In this case the values are negative because the net shortwave flux (defined as positive in the downward direction) for cloudy skies is smaller than for clear skies due to the cloud reflectivity. The excessive upper level cloud cover in the SUB run yields too much SW reflection and therefore the domainaverage SW values are about $40 \mathrm{~W} \mathrm{~m}^{-2}$ lower than observed. The MIC scheme, by reducing the upper level cloud cover, reduces the upward SW flux and therefore yields values 


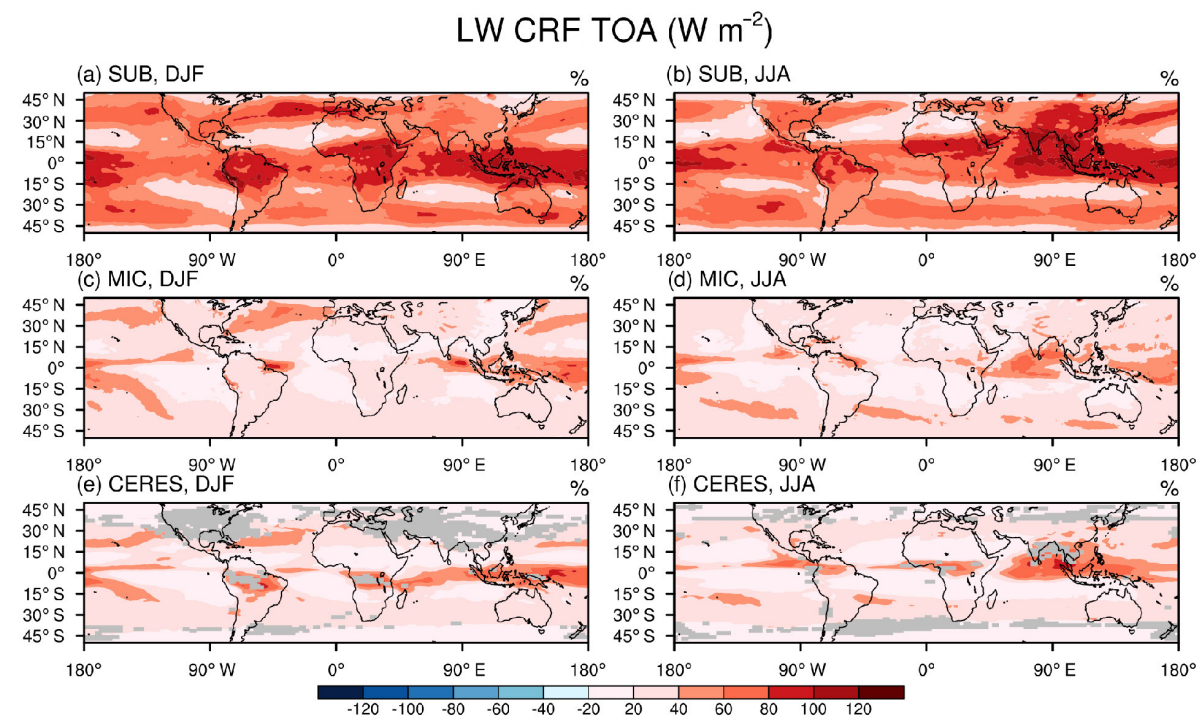

Figure 6. Simulated 10-year mean TOA LW radiation budget for DJF (left panels) and JJA (right panels) by SUB and MIC and CERES observations. Grey areas indicate missing values.

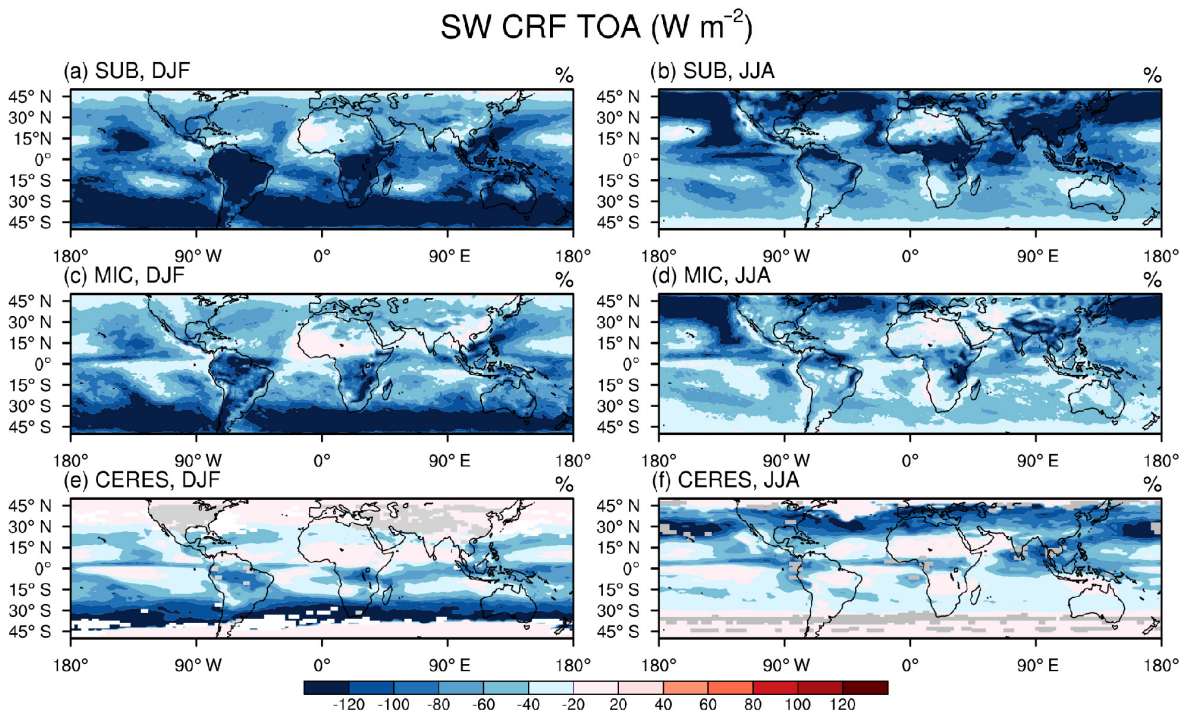

Figure 7. Simulated 10-year mean TOA SW radiation budget for DJF (left panels) and JJA (right panels) by SUB and MIC and CERES observations. Grey areas indicate missing values.

closer to observations (domain average bias of $10 \mathrm{~W} \mathrm{~m}^{-2}$ ). However, a substantial bias still persists in areas where both high and low clouds are well represented (e.g. around $45^{\circ} \mathrm{S}$ ). This bias can be attributed to the underestimation of thin low clouds as shown by the MISR simulator analysis (Fig. 5). Even if the overestimation of low cloud reflectivity is a common problem for many GCMs (e.g. Nam et al., 2012; Zhang et al., 2005), a reason for our overestimation of low optically thick clouds can be related to the coarse horizontal resolution $(100 \mathrm{~km})$ which does not resolve surface-heterogeneity, topography, and shallow mesoscale circulations. Future studies will evaluate the model performance at higher horizontal resolutions. When looking at the full CRF, i.e. the sum of $\mathrm{CRF}_{\mathrm{SW}}$ and $\mathrm{CRF}_{\mathrm{LW}}$ (Fig. 8 and Table 4), we see that essentially the model biases tend to compensate, yielding values close to each other for the two schemes and not far from observations (although on a domain average the MIC is still closer to observations by a few $\mathrm{W} \mathrm{m}^{-2}$ ). In some tropical monsoon regions the longwave gain in the SUB scheme appears to be larger than the shortwave loss, leading to an overall heating which is less pronounced in the MIC scheme. To summarize the findings of this section, the new cloud parameterization has a strong effect (leading to closer agreement with observations) on the partitioning of the CRF in 


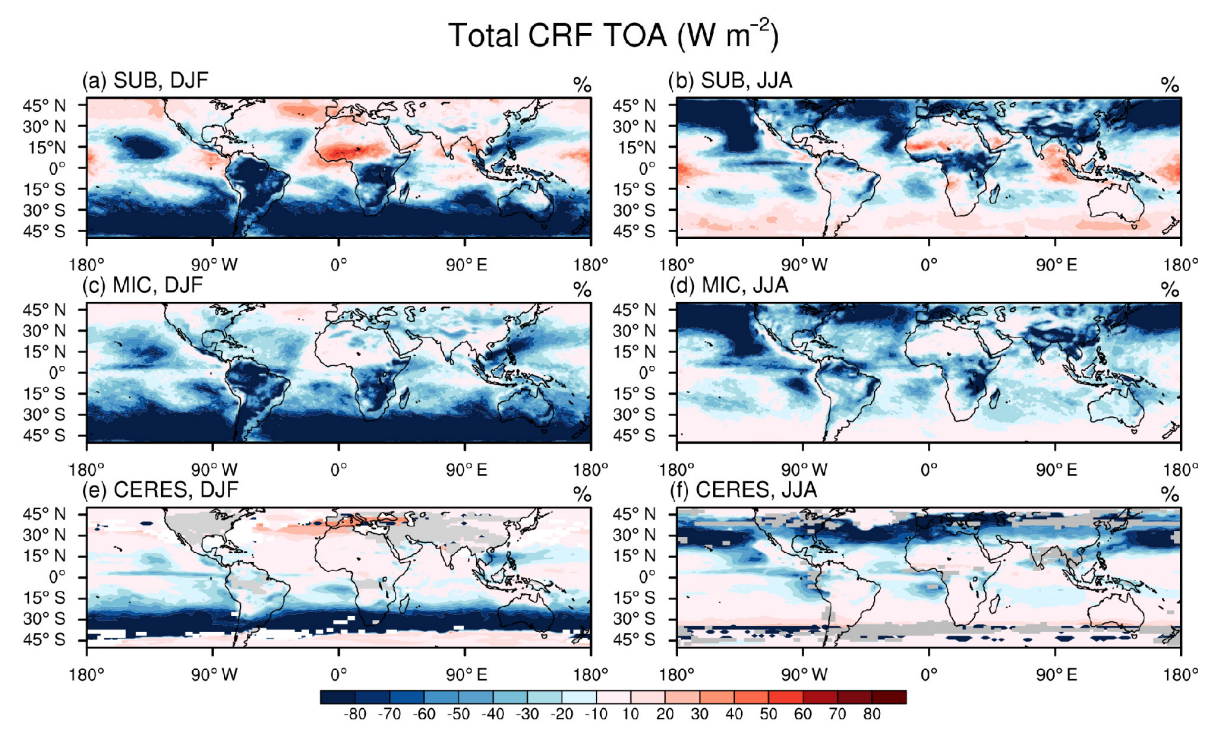

Figure 8. Simulated 10-year mean net TOA CRF for DJF (left panels) and JJA (right panels) by SUB and MIC and CERES observations. Grey areas indicate missing values.

Table 4. Global means of MIC and SUB radiation fields vs. observations.

\begin{tabular}{lrrr}
\hline Fields & RegCM4: MIC & RegCM4: SUB & Obs: CERES \\
\hline TOA CRF $_{\text {LW JJA }\left(\mathrm{W} \mathrm{m}^{-2}\right)}$ & 28.8 & 58.3 & 20.6 \\
TOA CRF $_{\mathrm{LW}}$ DJF $\left(\mathrm{W} \mathrm{m}^{-2}\right)$ & 29.9 & 59.6 & 21.2 \\
TOA CRF $_{S W}$ JJA $\left(\mathrm{W} \mathrm{m}^{-2}\right)$ & -50.1 & -82.4 & -40.8 \\
TOA CRF $_{\mathrm{LW}}$ DJF $\left(\mathrm{W} \mathrm{m}^{-2}\right)$ & -53.4 & -85.3 & -40.6 \\
TOA CRF $_{\text {tot }}$ JJA $\left(\mathrm{W} \mathrm{m}^{-2}\right)$ & -21.3 & -24.1 & -20.2 \\
TOA CRF $_{\text {tot }}$ DJF $\left(\mathrm{W} \mathrm{m}^{-2}\right)$ & -23.5 & -25.7 & -19.3 \\
\hline
\end{tabular}

its shortwave and longwave components, although the total cloud forcing is similar to that of the old scheme due to cancellation of biases. This is mostly attributed to the reduction of high level clouds found in the previous section.

\section{Summary and conclusion}

We here present the new resolved cloud microphysical parameterization implemented in regional climate model RegCM4 and some of the improvements that the new scheme brings to the model. To test the scheme we intercompared two 10-year simulations using the RegCM4 with and without the new scheme over a tropical band domain. Our main results can be summarized as follows.

1. The new microphysics scheme (MIC) did not have a strong effect on simulated precipitation, although, compared to the original SUBEX scheme (SUB), it generally reduced precipitation amounts over land and increased them over ocean. In some cases this led to a better agreement with observations, while in others it worsened this agreement. In view of the model sensitivity to different precipitation schemes and of the uncertainty in precipitation observation products, an unambiguous assessment of the effect of the new scheme on the model performance in simulating precipitation requires large ensembles of model simulations and is left for future work.

2. Conversely, the new scheme had a strong effect on the simulation of cloudiness, and in particular it produced a decrease in simulated upper level thin cirrus clouds, which increased agreement with observations and led to an amelioration of a long-standing problem in the RegCM system (e.g. Giorgi et al., 1999). In general, the new scheme improved the vertical cloud profile in the model.

3. Despite having a small effect on the total CRF, the new scheme considerably improved its partitioning into longwave and shortwave components. This is mostly because of the reduction of the upper level cloud bias in the original scheme noted above.

The preliminary tests described here of the new microphysics scheme introduced in RegCM4 provide encouraging indica- 
tions of its usefulness in improving the description of precipitation and especially cloud processes in the model. In particular, the fact that the main effect of the scheme is found in the simulation of high level clouds suggests that the inclusion of ice physics plays an important role in improving the model performance. More comprehensive sets of experiments are obviously needed in order to test the scheme in different model settings, especially towards its use in very high resolution, convection permitting simulations. We also need to assess the scheme's sensitivity to the use of different physics options in the model, particularly convection. All these issues are left for future work within the user community of the RegCM4 system. We also stress how the implementation of the COSP post-processing program within the RegCM4 framework represents a new important tool for future research on the model representation of clouds and the hydrologic cycle.

\section{Code availability}

The code is available under GPL v2 license as part of the RegCM codebase from version 4.4 onward from the ICTP gforge website: http://gforge.ictp.it/gf/project/regcm/ frs (Giorgi et al., 2012).

Acknowledgements. We would like to thank three anonymous reviewers for their constructive comments which have significantly improved the quality of this article.

Edited by: S. Remy

Reviewed by: three anonymous referees

\section{References}

Beheng, K.: A parameterization of warm cloud microphysical conversion processes, Atmos. Res., 33, 193-206, 1994.

Bodas-Salcedo, A., Webb, M., Bony, S., Chepfer, H., Dufresne, J.L., Klein, S., Zhang, Y., Marchand, R., Haynes, J., Pincus, R., and John, V. O.: COSP: Satellite simulation software for model assessment, B. Am. Meteorol. Soc., 92, 1023-1043, 2011.

Bretherton, C., McCaa, J., and Grenier, H.: A new parameterization for shallow cumulus convection and its application to marine subtropical cloud-topped boundary layers. Part I: Description and 1D results, Mon. Weather Rev., 132, 864-882, 2004.

Cesana, G., Waliser, D., Jiang, X., and Li, J.-L.: Multimodel evaluation of cloud phase transition using satellite and reanalysis data, J. Geophys. Res.-Atmos., 120, 7871-7892, 2015.

Chepfer, H., Bony, S., Winker, D., Cesana, G., Dufresne, J., Minnis, P., Stubenrauch, C., and Zeng, S.: The GCM-Oriented CALIPSO Cloud Product (CALIPSO-GOCCP), J. Geophys. Res.-Atmos., 115, 1-13, 2010.

Coppola, E., Giorgi, F., Mariotti, L., and Bi, X.: RegT-Band: a tropical band version of RegCM4, Clim. Res., 2, 115-133, 2012.

Coppola, E., Giorgi, F., Raffaele, F., Fuentes-Franco, R., Giuliani, G., LLopart-Pereira, M., Mamgain, A., Mariotti, L., Diro, G. T., and Torma, C.: Present and future climatologies in the phase I CREMA experiment, Climatic Change, 125, 23-38, 2014.

de Boer, G., Eloranta, E. W., and Shupe, M. D.: Arctic mixed-phase stratiform cloud properties from multiple years of surface-based measurements at two high-latitude locations, J. Atmos. Sci., 66, 2874-2887, 2009.

Dee, D., Uppala, S., Simmons, A., Berrisford, P., Poli, P., Kobayashi, S., Andrae, U., Balmaseda, M., Balsamo, G., Bauer, P., Bechtold, P., Beljaars, A. C. M., van de Berg, L., Bidlot, J., Bormann, N., Delsol, C., Dragani, R., Fuentes, M., Geer, A. J., Haimberger, L., Healy, S. B., Hersbach, H., Holm, E. V., Isaksen, L., Kallberg, P., Kohler, M., Matricardi, M., McNally, A. P., Monge-Sanz, B. M., Morcrette, J.-J., Park, B.-K., Peubey, C., deRosnay, P., Tavolato, C., Thepaut, J.-N., and Vitart, F.: The ERA-Interim reanalysis: Configuration and performance of the data assimilation system, Q. J. Roy. Meteor. Soc., 137, 553-597, 2011.

DelGenio, A., Yao, M., Kovari, W., and Lo, K.: A prognostic cloud water parameterization for global climate models, J. Climate, 9, 270-304, 1996.

Dickinson, R., Kennedy, P., and Henderson-Sellers, A.: Biosphereatmosphere transfer scheme (BATS) version 1e as coupled to the NCAR community climate model, National Center for Atmospheric Research, Climate and Global Dynamics Division, 1993.

Diro, G. T., Rauscher, S. A., Giorgi, F., and Tompkins, A. M.: Sensitivity of seasonal climate and diurnal precipitation over Central America to land and sea surface schemes in RegCM4, Clim. Res., 2, 31-48, 2012a.

Diro, G. T., Tompkins, A. M., and Bi, X.: Dynamical downscaling of ECMWF Ensemble seasonal forecasts over East Africa with RegCM3, J. Geophys. Res., 117, D16103, doi:10.1029/2011JD016997, 2012b.

Forbes, R. M., Tompkins, A. M., and Untch, A.: 649: A new prognostic bulk microphysics scheme for the IFS, Tech. rep., European Centre for Medium-Range Weather Forecasts, available at: http://www.ecmwf.int/publications (last access: 22 July 2016), 2011.

Fowler, L., Randall, D., and Rutledge, S.: Liquid and ice cloud microphysics in the CSU general circulation model. Part I: Model description and simulated cloud microphysical processes, J. Climate, 9, 489-529, 1996.

Franklin, C., Sun, Z., Bi, D., Dix, M., Yan, H., and Bodas-Salcedo, A.: Evaluation of clouds in ACCESS using the satellite simulator package COSP: Global, seasonal, and regional cloud properties, J. Geophys. Res.-Atmos., 118, 732-748, 2013.

Fuentes-Franco, R., Coppola, E., Giorgi, F., Graef, F., and Pavia, E. G.: Assessment of RegCM4 simulated inter-annual variability and daily-scale statistics of temperature and precipitation over Mexico, Clim. Dynam., 42, 629-647, 2014.

Giorgi, F., Marinucci, M. R., Bates, G. T., and De Canio, G.: Development of a second-generation regional climate model (RegCM2). Part II: Convective processes and assimilation of lateral boundary conditions, Mon. Weather Rev., 121, 2814-2832, 1993.

Giorgi, F., Huang, Y., Nishizawa, K., and Fu, C.: A seasonal cycle simulation over eastern Asia and its sensitivity to radiative transfer and surface processes, J. Geophys. Res.-Atmos., 104, 64036423, 1999. 
Giorgi, F., Coppola, E., Solmon, F., Mariotti, L., Sylla, M., Bi, X., Elguindi, N., Diro, G., Nair, V., Giuliani, G., Turuncoglu, U., Cozzini, S., Güttler, I., O’Brien, T., Tawfik, A., Shalaby, A., Zakey, A., Steiner, A., Stordal, F., Sloan, L., and Brankovic, C.: RegCM4: model description and preliminary tests over multiple CORDEX domains, Clim. Res., 2, 7-29, 2012 (code available at: http://gforge.ictp.it/gf/project/regcm/frs).

Grell, G., Dudhia, A., and Stauffer, D.: Description of the fifth generation Penn State/NCAR Mesoscale Model(MM5), Tech. Rep. TN-398+STR, NCAR, Boulder, Colorado, 1994.

Hsie, E.-Y. and Anthes, R. A.: Simulations of frontogenesis in a moist atmosphere using alternative parameterizations of condensation and precipitation, J. Atmos. Sci., 41, 2701-2716, 1984.

Huffman, G. J., Bolvin, D. T., Nelkin, E. J., Wolff, D. B., Adler, R. F., Gu, G., Hong, Y., Bowman, K. P., and Stocker, E. F.: The TRMM multisatellite precipitation analysis (TMPA): Quasiglobal, multiyear, combined-sensor precipitation estimates at fine scales, J. Hydrometeorol., 8, 38-55, 2007.

Kärcher, B. and Lohmann, U.: A parameterization of cirrus cloud formation: Homogeneous freezing of supercooled aerosols, J. Geophys. Res., 107, AAC 4-1-AAC 4-10, 2002.

Kessler, E.: On the distribution and continuity of water substance in atmospheric circulation, Meteor. Monogr., American Meteorological Society, 32, 1969.

Khairoutdinov, M. and Kogan, Y.: A new cloud physics parameterization in a large-eddy simulation model of marine stratocumulus, B. Am. Meteorol. Soc., 128, 229-243, 2000.

Komurcu, M., Storelvmo, T., Tan, I., Lohmann, U., Yun, Y., Penner, J. E., Wang, Y., Liu, X., and Takemura, T.: Intercomparison of the cloud water phase among global climate models, J. Geophys. Res.-Atmos., 119, 3372-3400, 2014.

Koop, T., Luo, B., Tsias, A., and Peter, T.: Water activity as the determinant for homogeneous ice nucleation in aqueous solutions, Nature, 406, 611-614, 2000.

Korolev, A. V., Isaac, G. A., Cober, S. G., Strapp, J. W., and Hallett, J.: Microphysical characterization of mixed-phase clouds, Q. J. Roy. Meteor. Soc., 129, 39-65, 2003.

Lin, Y., Farley, R., and Orville, H.: Bulk parameterization of the snow field in a cloud model, J. Appl. Meteor. Clim., 22, 10651092, 1983.

Liu, Y. and Daum, P.: Parameterization of the autoconversion process. part I: Analytical formulation of the Kessler-type parameterizations, J. Atmos. Sci., 61, 1539-1548, 2004.

Lohmann, U. and Roeckner, E.: Design and performance of a new cloud microphysics scheme developed for the ECHAM general circulation model, Clim. Dynam., 12, 557-572, 1996.

Marchand, R., Ackerman, T., Smyth, M., and Rossow, W.: A review of cloud top height and optical depth histograms from MISR, ISCCP, and MODIS, J. Geophys. Res.-Atmos., 115, D16206, doi:10.1029/2009JD013422, 2010.

Matveev, L.: Cloud Dynamics, 340 pp, D. Reidel, Norwell, Mass, 1984.

Meyers, M. P., DeMott, P. J., and Cotton, W. R.: New primary icenucleation parameterizations in an explicit cloud model, J. Appl. Meteorol., 31, 708-721, 1992.

Muller, J.-P., Mandanayake, A., Moroney, C., Davies, R., Diner, D., and Paradise, S.: MISR stereoscopic image matchers: Techniques and results, IEEE T. Geosci. Remote Sens., 40, 1547-1559, 2002.
Nam, C., Bony, S., Dufresne, J.-L., and Chepfer, H.: The "too few, too bright" tropical low-cloud problem in CMIP5 models, Geophys. Res. Lett., 39, L21801, doi:10.1029/2012GL053421, 2012.

Naud, C., Muller, J.-P., and Clothiaux, E.: Comparison of cloud top heights derived from MISR stereo and MODIS $\mathrm{CO}_{2}$-slicing, Geophys. Res. Lett., 29, 42-1-42-4, doi:10.1029/2002GL015460, 2002.

Nikulin, G., Jones, C., Giorgi, F., Asrar, G., Büchner, M., CerezoMota, R., Christensen, O. B., Déqué, M., Fernandez, J., Hänsler, A., van Meijgaard, E., Samuelsson, P., Sylla, M. B., and Sushama, L.: Precipitation climatology in an ensemble of CORDEX-Africa regional climate simulations, J. Climate, 25, 6057-6078, 2012.

Nogherotto, R.: A numerical framework for multiple phase cloud microphysics in regional and global atmospheric models, Università degli studi di Trieste, Italy, 2015.

Nogherotto, R., Coppola, E., Giorgi, F., and Mariotti, L.: Impact of Congo Basin deforestation on the African monsoon, Atmos. Sci. Lett., 14, 45-51, 2013.

Pal, J., Small, E., and Eltahir, E.: Simulation of regional-scalewater and energy budgets: representation of subgridcloud and precipitation processes within RegCM, J. Geophys. Res., 105, 29579 29594, 2000.

Prein, A. F., Langhans, W., Fosser, G., Ferrone, A., Ban, N., Goergen, K., Keller, M., Tölle, M., Gutjahr, O., Feser, F., Brisson, E., Kollet, S., Schmidli, J., van Lipzig, N. P. M., and Leung, R.: A review on regional convection-permitting climate modeling: demonstrations, prospects, and challenges, Rev. Geophys., 53, 323-361, doi:10.1002/2014RG000475, 2015.

Ramanathan, V., Cess, R., Harrison, E., Minnis, P., Barkstrom, B., Ahmad, E., and Hartmann, D.: Cloud-radiative forcing and climate: Results from the Earth Radiation Budget Experiment, Science, 243, 57-63, 1989.

Rossow, W., Beuschel, D., and Roiter, M.: International Satellite Cloud Climatology Project (ISCCP) documentation of new cloud datasets, World Climate Research Programme, NASA, Goddard Institute of Space Studies, p. 15, 1996.

Rotstayn, L.: A physically based scheme for the treatment of stratiform clouds and precipitation in large-scale models. I: Description and evaluation of the microphysical processes, Q. J. Roy. Meteorol. Soc., 123, 1227-1282, 1997.

Rotstayn, L., Ryan, B., and Katzfey, J.: A scheme for calculation of the liquid fraction in mixed-phase stratiform clouds in large-scale models, Mon. Weather Rev., 128, 1070-1088, 2000.

Simmons, A., Uppala, S., Dee, D., and Kobayashi, S.: ERA-Interim: New ECMWF reanalysis products from 1989 onwards, ECMWF newsletter, 110, 25-35, 2007.

Sud, Y. C., Lee, D., Oreopoulos, L., Barahona, D., Nenes, A., and Suarez, M. J.: Performance of McRAS-AC in the GEOS5 AGCM: aerosol-cloud-microphysics, precipitation, cloud radiative effects, and circulation, Geosci. Model Dev., 6, 57-79, doi:10.5194/gmd-6-57-2013, 2013.

Sundqvist, H.: A parameterization scheme for non-convective condensation including prediction of cloud water content, Q. J. Roy. Meteorol. Soc., 104, 677-690, 1978.

Sundqvist, H., Berge, E., and Kristjansson, J.: Condensation and cloud parameterization studies with a mesoscale numerical weather prediction model, Mon. Weather Rev., 117, 1641-1657, 1989. 
Swann, H. A.: Cloud microphysical processes - a description of the parameterization used in the Large Eddy Model, Tech. rep., UK Meteorological Office, 1994.

Sylla, M., Giorgi, F., Coppola, E., and Mariotti, L.: Uncertainties in daily rainfall over Africa: assessment of gridded observation products and evaluation of a regional climate model simulation, Int. J. Climatol., 33, 1805-1817, 2013.

Sylla, M. B., Coppola, E., Mariotti, L., Giorgi, F., Ruti, P., Dell'Aquila, A., and Bi, X.: Multiyear simulation of the African climate using a regional climate model (RegCM3) with the high resolution ERA-interim reanalysis, Clim. Dynam., 35, 231-247, 2010.

Tiedtke, M.: A comprehensive mass flux scheme for cumulus parameterization on large scale models, Mon. Weather Rev., 117, 1779-1800, 1989.

Tiedtke, M.: Aspects of cumulus parametrization, Proc. ECMWF Seminar on Tropical Extra-Tropical Interactions, Reading, UK, 1991.

Tiedtke, M.: Representation of clouds in large-scale models, Mon. Weather Rev., 121, 3040-3061, 1993.

Tompkins, A.: A prognostic parameterization for the subgrid-scale variability of water vapour and clouds in large- scale models and its use to diagnose cloud cover, J. Atmos. Sci., 59, 1917-1942, 2002.

Tompkins, A.: Ice supersaturation in the ECMWF integrated forecast system, Q. J. Roy. Meteor. Soc., 133, 53-63, 2007.

Tompkins, A. M.: The parameterization of cloud cover, ECMWF Technical Memorandum, 1-25, 2005a.
Tompkins, A. M.: Revised cloud scheme to reduce sensitivity to vertical resolution, Tech. rep., European Centre for Medium-Range Weather Forecasts, 2005b.

Wielicki, B. A.: CERES ERBE-like Monthly Geographical Averages (ES-4) in HDF (CER_ES4_Terra-FM1_Edition2), available at: http://eosweb.larc.nasa.gov/ (last access: 22 July 2016), 2011.

Wilson, D. and Ballard, S.: A microphysically based precipitation scheme for the UK Meteorological Office Unified Model, Q. J. Roy. Meteor. Soc., 125, 1607-1636, 1999.

Winker, D., Pelon, J., Coakley, J. J., Ackerman, S., Charlson, R., Colarco, P., Flamant, P., Fu, Q., Hoff, R., Kittaka, C., Kubar, T. L., Le Treut, H., Mccormick, M. P., Megie, G., Poole, L., Powell, K., Trepte, C., Vaughan, M. A., and Wielicki, B. A.: The CALIPSO mission: A global 3D view of aerosols and clouds, B. Am. Meteorol. Soc., 91, 1211-1229, doi:10.1175/2010BAMS3009.1, 2010.

$\mathrm{Xu}, \mathrm{K}$. and Randall, D.: A semiempirical cloudiness parameterization for use in climate models, J. Atmos. Sci., 53, 3084-3102, 1996.

Zhang, M., Lin, W., Klein, S., Bacmeister, J., Bony, S., Cederwall, R., Del Genio, A., Hack, J., Loeb, N., Lohmann, U., Minnis, P., Musat, I., Pincus, R., Stier, P., Suarez, M. J., Webb, M. J., Wu, J. B., Xie, S. C., Yao, M.-S., and Zhang, J. H.: Comparing clouds and their seasonal variations in 10 atmospheric general circulation models with satellite measurements, J. Geophys Res.-Atmos., 110, D15S02, doi:10.1029/2004JD005021, 2005. 